\title{
MICROFABRICATION OF POROUS STRUCTURE BY TEMPLATE METHOD
}

\author{
テンアレート法によるる孔槽造の微細加エ \\ Nobuyoshi BABA and Hideki MASUDA \\ Faculty of Technology, Tokyo Metropolitan Univ. \\ 1-1 Minami-Osawa, Hachioji-City, Tokyo 192-03 JAPAN \\ TEL: 81-426-77-1111 FAX:81-426-77-2841 \\ (Received 8, July $1993 \quad$ Accepted 11, August 1993)
}

\begin{abstract}
Microporous structure of anodized alumina films formed in an acid electrolyte has been duplicated to other materials in high fidelity. In anodic oxidation of aluminum, the size and number of the micropores can precisely be controlled by the applied voltage, the kind and the concentration of the electrolyte used. The duplication of this microstructure is established by either electrodeposition of metals, chemical deposition of metals, sol-gel method or replica method using polymerization of resin.

The duplicated materials can be applied to the functional electrodes, optical grating film, microfilters or columnarly blent composite resin.
\end{abstract}

Key wards: Porous alumina,Template, Microfilter, Functional electrode

\section{INTRODUCTION}

Porous type anodic oxide films on aluminum is a unique material for its microporous structure. Isolated and non-crossing microropore array is open perpendicular to the oxide surface. The size and number of the micropores can be controled by electrolysis conditions. To obtain such an oxide film, aluminum sheet is anodically oxidized in an oxalic acid electrolyte at $27^{\circ} \mathrm{C}$, then porous anodic oxide film having pore diameters of 10-50 nm can be obtained.

Since the anodic alumina film is mainly composed of amorphous $\mathrm{Al}_{2} \mathrm{O}_{3}$, it is easily attacked by both acids and bases. The anodized alumina thin film is also very brittle and breakable.
To avoid these weak points, we have developed the replication of the porous structure by other stable materials, such as precious metals, semi-conductors, or plastics. $1-8$

As replication methods, we have developed several methods, that is: electrodeposition, chemical deposition of metals, sol-gel method and polymerization of MMA resin(metyl methacrylate). The aspect ratio of the porous structure reached 70 in the case of the pore diameter of $50 \mathrm{~nm}$. The porous film thus obtained can be used as a supporting material for enzyme functional electrode, ultramicroporous separation membranes, 9-11 and columnarly blent composite materials.

(C) 1993 Society of Advanced Science 


\section{FORMATION OF ANODIC OXIDE FILMS ON ALUMINUM}

99.99\% aluminum sheet is electrochemically polished in a perchloric acid-ethanol mixed solution at a temperature lower than $5^{\circ} \mathrm{C}$ with gentle stirring. To obtain uniform and regular array of micropores, the surface of aluminum must be microscopically flat and mirror bright. By this pre-treatment the oxide film existing on the aluminum surface is removed and the surface becomes chemically clean. Then the pre-treated aluminum sheet is anodically polarized in a $0.5 \%$ oxalic acid electrolyte at a constant temperature of $27^{\circ} \mathrm{C}$ and at a constant bath voltage. In this process the size of the pore diameter is mainly determined by the bath voltage and partly the bath temperature and the concentration of the electrolyte.

Fig. 1 shows the relationship between the electrolysis voltages and pore diameter in the case of the $3 \%$ oxalic acid electrolyte at $20^{\circ} \mathrm{C} .12$ The pore diameter is almost proportional to the bath voltage.



Fig. 1 Relation between the pore diameter of anodic oxide film on $\mathrm{Al}$ and electrolysis voltage

A typical SEM image of the porous anodic alumina film formed in an oxalic acid electrolyte is shown in Fig.2.

The micropores are open perpendicu- lar to the surface and parallel each other without intercrossing or baranching. The bottom of the pores are closed by the underlying so called barrier layer. To impregnate metals in the pores by the electrodeposition method, this barrier layer should be removed or thin enough so that the electric current is allowed to flow.

The modification of this porous structure is mentionsd in the next section and schematically shown in Figs. 3a, 3b, and 3c.

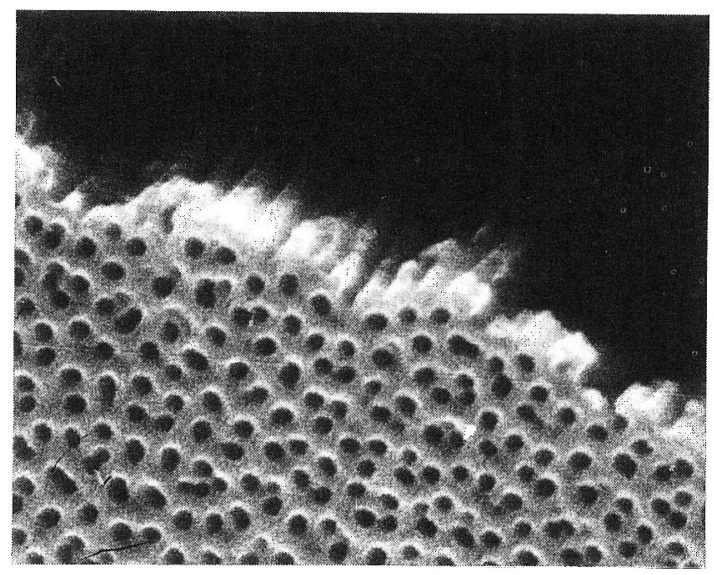

Fig.2 Typical SEM image of porous anodized alumina film

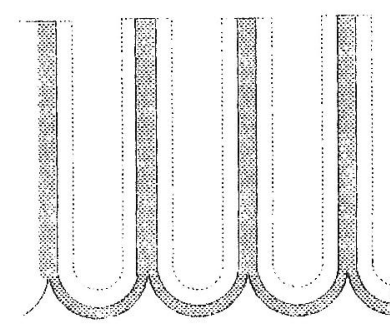

(a) Pore widening



(b) Pore filling

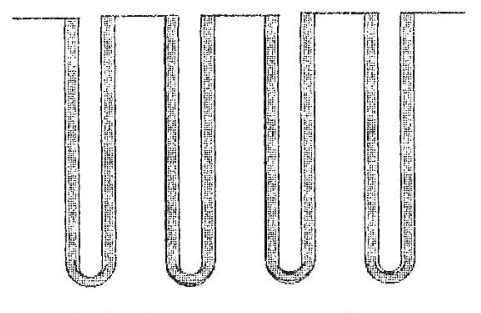

(c) Pore narrowing

Fig. 3 Modification of porous alumina films 


\section{MODEFICATIONS OF THE POROUS STRUCTURES}

\subsection{THINNING OF THE BARRIER LAYER}

When the anodized alumina film

is allowed to stand in the same electrolyte under reduced applied voltage, the current flow temporarily becomes almost zero for several minutes and then gradually recovers reaching a new value, as is seen in Fig. 4.

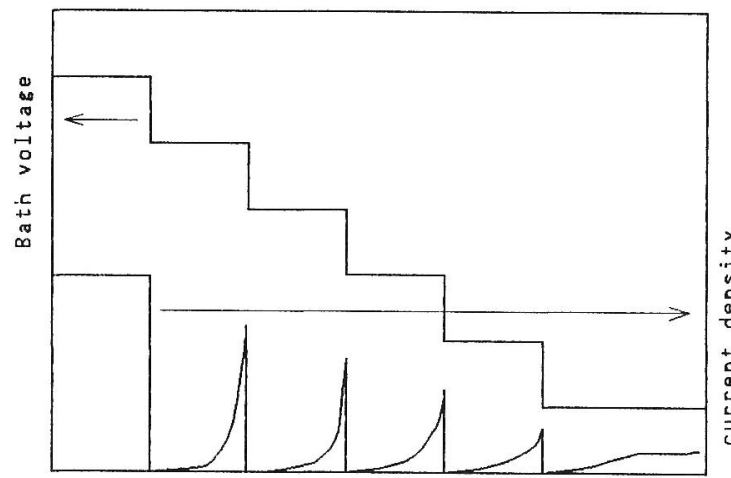

Duration of electrolysis by recovery process

Fig. 4 Schematic figure of current recovery process

During this period, the bottom of the micropores dissolves. This process is repeated several times until the applied voltage of lower than 2 volt, the thickness of the barrier layer is becomming less than $3 \mathrm{~nm}$. Thus the barrier layer is no more acting as the barrier of the electric current and the electrodeposition of metals is easy to proceed.

\subsection{PORE FILLING AND PORE WIDENING}

Porous structure of the anodic oxide film can be modified by pore filling or pore widening process as the post-treatment.

When the porous anodized alumina is re-anodized in a neutral borate electrolyte, the bottom part of the porous structure is filled with the non-porous alumina layer as shown in Fig. 3b.

On the other hand, the porous anodized alumina film is immersed in an acid solution without applying electric potentials, the inside surface of the micropores is gradually attacked by the acid, and the pore diameter is enlarged (Fig.3a). In this manner the pore diameter can be controlled by the duration of immersion time in the acid solution.

Fig. 5 shows an example of trans

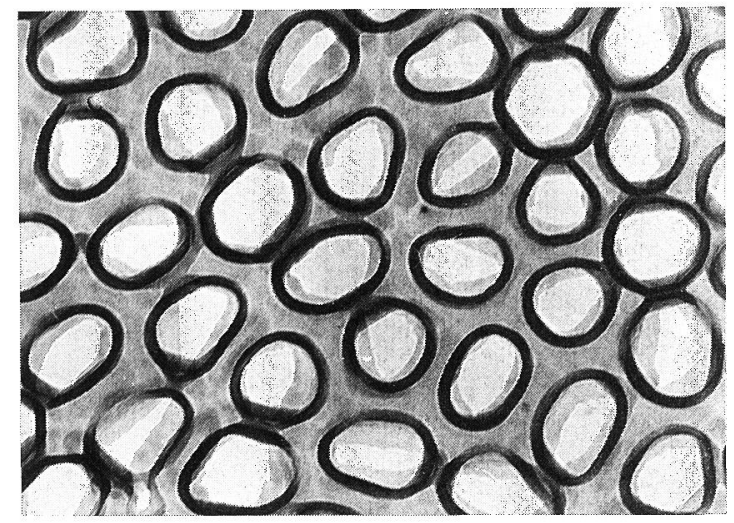

Fig.5 TEM image of widened porous alumina film formed in oxalic acid electrolyte

mission electron micrograph of the pore widened porous alumina films formed in an oxalic acid electrolyte.

\section{3 PORE NARROWING PROCESS}

When porous anodic alumina film is immersed in silica sol, the colloidal $\mathrm{SiO}_{2}$ is deposited in the micropores resulting the pore narrowing(Fig.3c).13 In the same way the alumina sol can be used. The coating of the $\mathrm{SiO}_{2}$ sol is also effective to make the pore wall inert, otherwise the pore wall is gradually hydrated by the atmospheric moisture(sealing effect). The CVD method is also used for the porous films. 14 It is however very difficult to impregnate the material in the pore bottom uniformly.

The deposition occurs only at the edge of the pore opening part.

\section{VARIOUS MICROFABRICATION METHODS OF POROUS STRUCTURE}

Fig. 6 shows the schematic procedures of several template methods. 


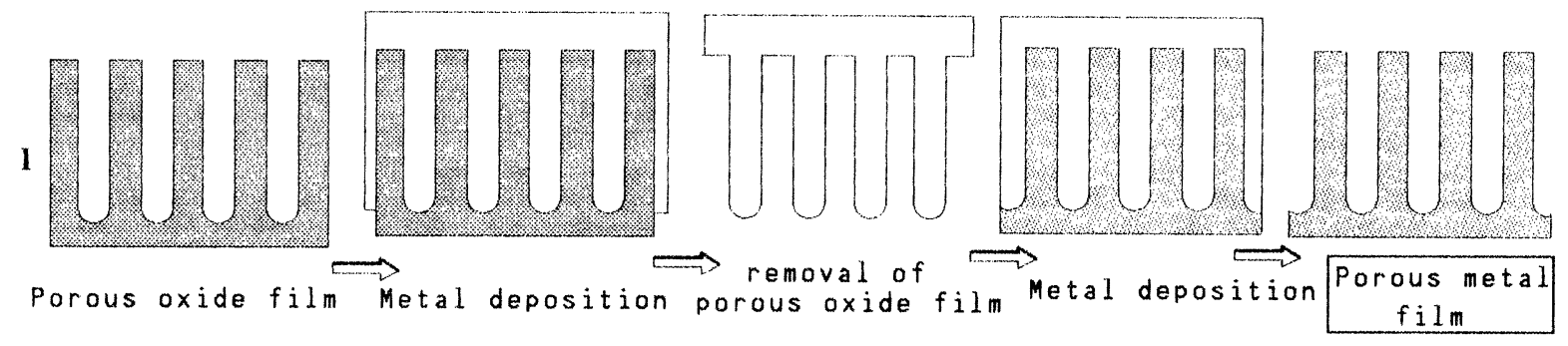

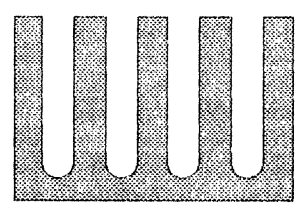

Porous oxide film

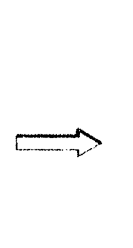

Vacuum evaporation with Pd

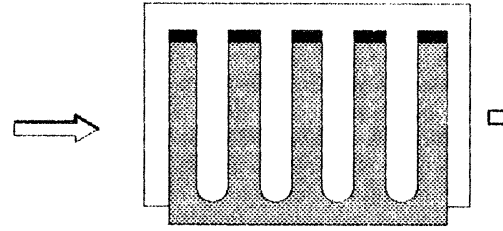

Impregntion with MMA (monomer)
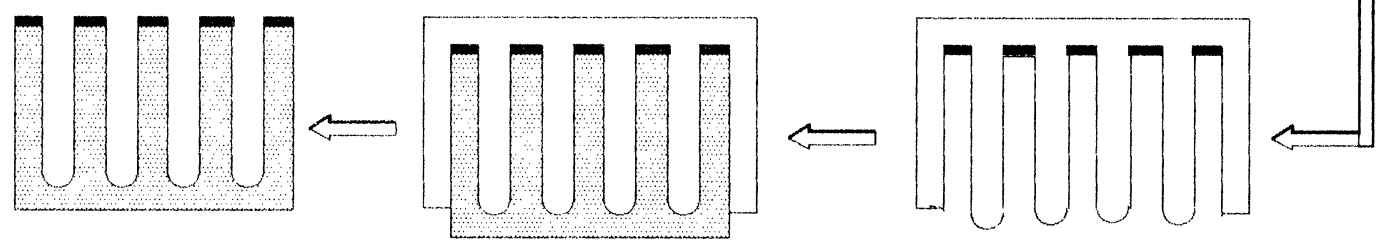

Porous Ni film

Electroless deposition of $\mathrm{Ni}$

Removal of oxide film
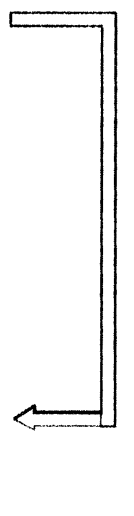

$$
\text { Removal of oxide film }
$$

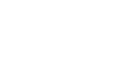
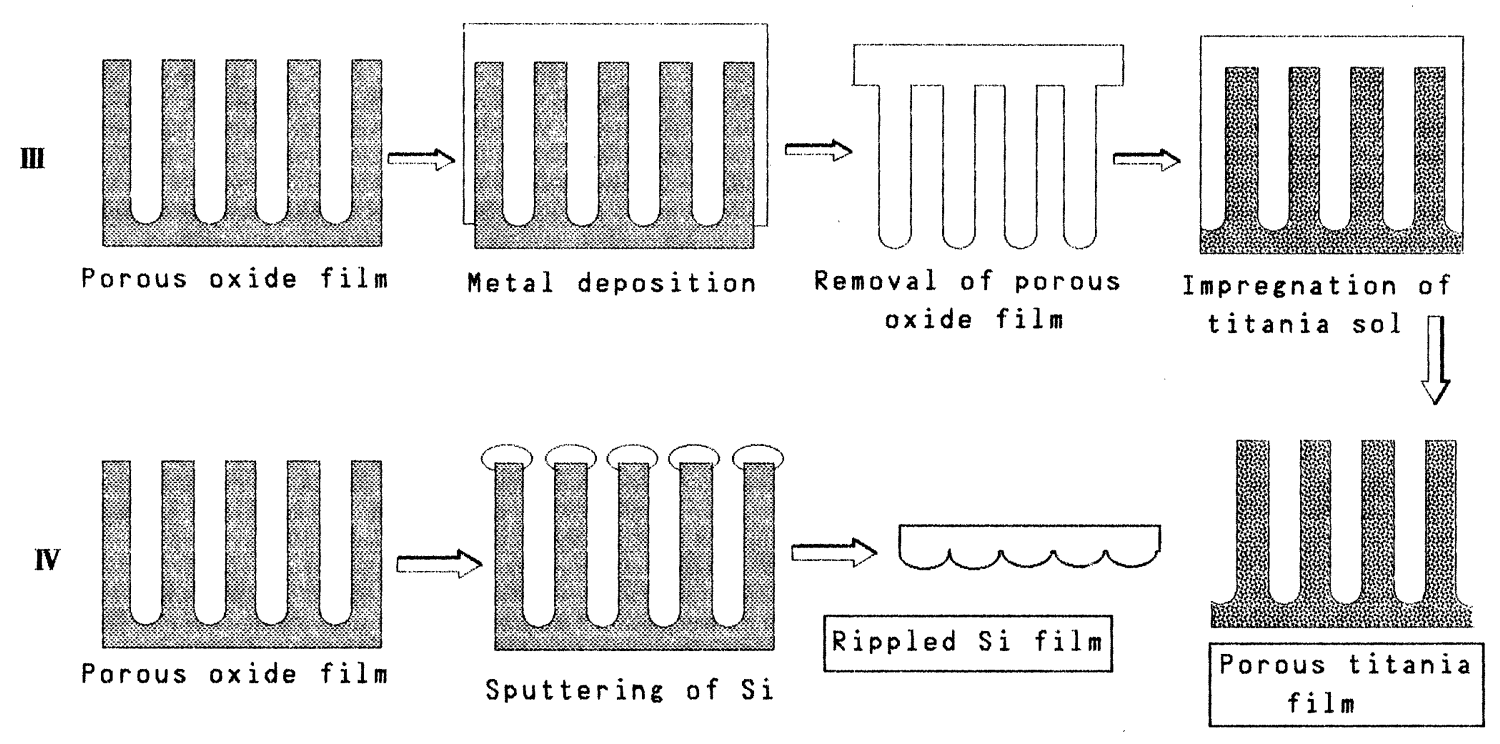

Fig.6. Schematic Procedures of Various Template Method 
We can duplicate the microporous structure of anodized alumina film by [1] electrodeposition of metals, [2] electroless deposition of metals, [3] sol-gel impregnation method, and [4] sputtering process.

Fig. 7 shows the SEM image of the microporous structure of negative type $\mathrm{Ni}$ needles produced by electroless deposition of metals. It is clearly seen that nickel columns are growing perpendicular to the substrate metal surface. This shape is exactly corresponding to the negative structure of the porous anodic oxide film.

Electrodeposition of precious metals on the negative type nickel colomns gave again the positive type porous structure of precious metals. By this process the porous structure of gold film can easily be obtained(Fig.8).

The porous metal surface impregnated with glucose oxitase enzyme is electrochemically active to the reduction of molecular oxygen dissolved in water, so that it is applicable to the glucose sensor.

Fig.9 shows the microfabrication process of porous silicon film on anodized alumina surface. Metallic silicon is Ar-ion sputtered on the anodized alumina film, and then the anodized alumina film is removed by $\mathrm{NaOH}$ solution. Porous structure of the anodized alumina surface is fairly good reproduced on the sputtered silicone surface as is shown in Fig.10.

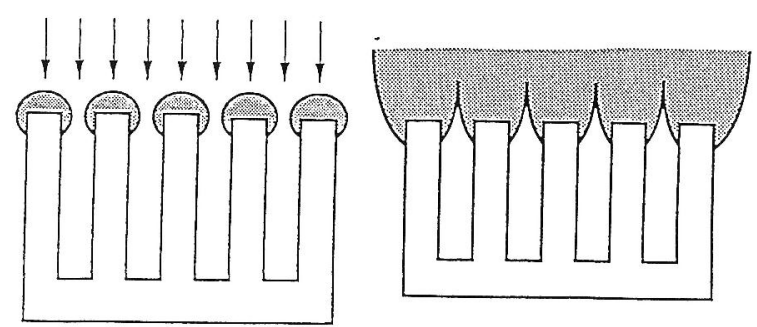

Fig. 9 Microfabrication process of porous silicone film

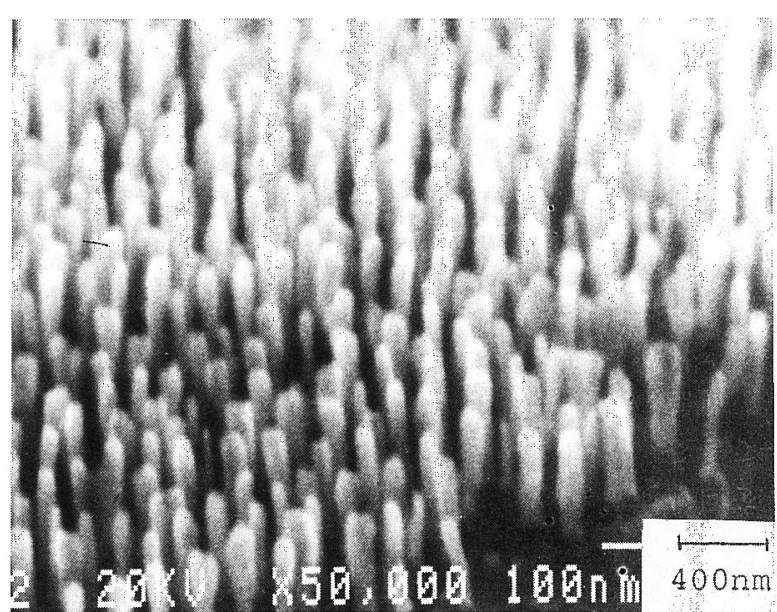

Fig.7 SEM image of $\mathrm{Ni}$ columns(Negative type of porous structure)

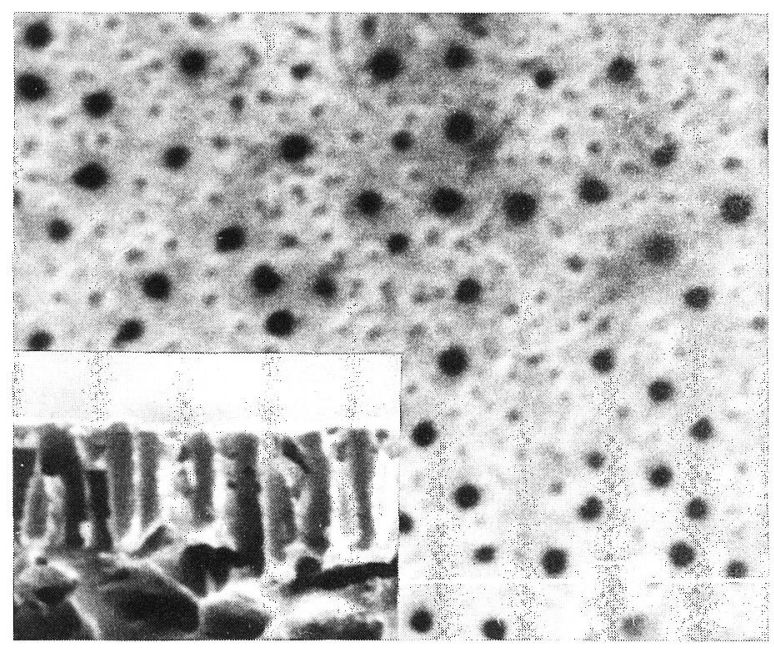

Fig.8 SEM image of porous Au film duplicated from porous alumina template



Fig.10 SEM image of porous silicone film duplicated by sputtering method 
Fig.11 shows the SEM image of the porous structure of polymer film fabricated by the 2 step template method. In this experiment, polyester resin has been investigated.

\section{FUTURE APPLICATIONS}

The porous structure of duplicated thin film can be used for

1] Semi-transparent electrode for the photo-electrochemical measure ments.

2] Selective ion separation membrane.

3] Supporting electrode of enzymes or liquid crystals.

4] Separation membrane of microbials or macromolecular substances

5] Composite film of microporous structure has possibility of multi-functional devices. 15,16

\section{ACKNOWLEDGEMENT}

Authors are indebted to the Light Metals Educational Foundations, Osaka, (Keikinzoku Shogakukai) for the financial support.

\section{REFERENCES}

1 H. MASUDA, K. NISHIO and N. BABA: Thin Solid Films, 223,1(1993)

2 H. MASUDA, K. NISHIO and N. BABA; Jpn.J.Appl.Phys. 31,L1775 (1992)

3 H. MASUDA, H. TANAKA and N. BABA; Bull.Chem.Soc., Jpn. 66,305(1993)

$4 \mathrm{H}$. MASUDA, K. NISHIO and N. BABA: submitted to the J.Appl. Phys.

$5 \mathrm{H}$. MASUDA, K. NISHIO and N. BABA: submitted to the Thin Solid Films

6 H. MASUDA, K. NISHIO and N. BABA; J.Surface Finishing Soc.Jpn., 43, No.8,798(1992)

7 H. MASUDA, H. TANAKA and N. BABA: Chem. Lett. 1990,621(1990)

8 H. MASUDA and N. BABA; J. Surface Finishing Soc.Jpn. 41, No.8,813 (1990)

9 K. KURODA; J.Surface Finishing Soc. Jpn. 40, No.5,685(1989)

10 S. MORISAKI, M. YAMAMURO and $\mathrm{N}$. BABA; J.Surface Finishing Soc. Jpn. 40 , No.1,152(1989)

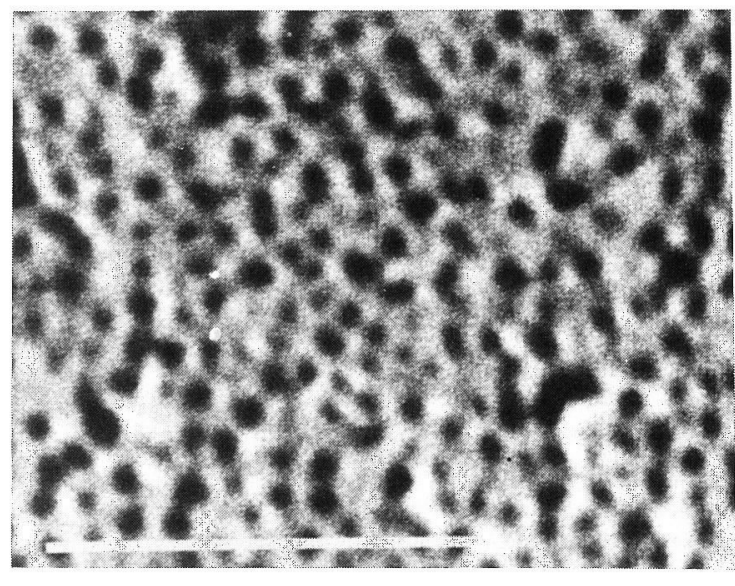

Fig.11 SEM image of porous polyester resin film duplicated from porous alumina template

11 S.ONO, Kenji WADA, T. YOSHINO, Kazuhiro WADA and N. BABA; J. Surface Finishing Soc.Jpn, 40, No.9,1039(1989)

$12 \mathrm{~S}$. ONO, N. BABA and N. MASUKO; J.Surf.Fin.Soc., Jpn. 42, No.1, 133(1991)

$13 \mathrm{~K}$. WADA, K. SHINGYOUCHI and A. MAKISHIMA: J.Suface Finishing. Soc.,Jpn. 40,No.12,1372(1989)

$14 \mathrm{H}$. MASUDA and N. BABA; J.Surface Finishing Soc.Jpn., 43, No.2, 150(1992)

15 s. KAWAI et al; J. Electrochem. Soc., 122,1026(1975), 123, $1047(1976)$

$16 \mathrm{~K}$. ARAI, H. W. KANG and $\mathrm{K}$. ISHIYAMA; J.Surface Finishing Soc.Jpn. , 42, No.3,291(1991)

Profile.

Nobuyoshi BABA,

Prof. Dr.

born in 19, Oct.1930, graduated from Tokyo Metropolitan Univ. in 1953

1961-1963 stayed in Forschungsinstitut für Edelmetalle und Metallchemie, West Germany as research associate.

Present research field:

surface science, electrochemistry, and energy sciences.

Academic activity; President of the Surface Science Society, Japan 